Shear and torsion interaction in prestressed hollow core units

H. Broo, K. Lundgren and B. Engström

Published in Magazine of Concrete Research, see journal homepage

http://www.icevirtuallibrary.com/content/journals

"Permission is granted by ICE Publishing to print one copy for personal use. Any other use of these PDF files is subject to reprint fees." 


\title{
Shear and torsion interaction in prestressed hollow core units
}

\author{
H. Broo, ${ }^{*}$ K. Lundgren* and B. Engström* \\ Chalmers University of Technology, Sweden
}

\begin{abstract}
Hollow core units are mainly designed to resist bending and shear. There are, however, many applications in which they are also subjected to torsion. The present calculation method for shear and torsion in the European Standard EN 1168 adds stresses from multiple influences without taking into account the softening of cracking concrete; therefore it is probably conservative. The main purpose of this work is to investigate the response of prestressed hollow core units subjected to selected combinations of shear and torsion by using non-linear finite element (FE) analyses. In previous work by the present authors, three-dimensional FE models of hollow core units were developed and validated by full-scale experiments. This paper shows how similar models were analysed for several load combinations of shear and torsion ratios. One load combination was validated by full-scale tests. The results from the FE analyses made it possible to present shear and torsion capacities in interaction diagrams useful in practical design. Moreover, the influences of the shear span and the prestressing transfer zone on the shear and torsion capacity were evaluated. It was concluded that the boundaries affected the capacity: shorter shear span gave higher capacity. The curved interaction diagrams obtained from the FE analyses were compared with linear diagrams from the analytical model in EN 1168. For most combinations the FE analyses showed higher capacities, except for combinations close to pure torsion, and pure shear for one of the geometries investigated.
\end{abstract}

\section{Notation}

$A$

total cross-sectional area (including inner hollow areas) of the transformed cross-section $\left(\mathrm{m}^{2}\right)$

$A_{\mathrm{c}} \quad$ cross-sectional area $\left(\mathrm{m}^{2}\right)$

$b \quad$ width at the centroidal axis $(\mathrm{m})$

$b_{\mathrm{w}, \mathrm{out}} \quad$ thickness of the outermost web (m)

$\sum b_{\mathrm{w}}$ the sum of the widths at the centroidal axis of all webs (m)

$d \quad$ effective depth (m)

$E_{\text {ci }} \quad$ modulus of elasticity of concrete

$E_{\mathrm{p}} \quad$ modulus of elasticity of prestressing steel

$e \quad$ eccentricity of the strands $(\mathrm{m})$

$f_{\text {ct }} \quad$ concrete tensile strength $(\mathrm{Pa})$

$I_{c} \quad$ second moment of area $\left(\mathrm{m}^{4}\right)$

$l_{\mathrm{pt}} \quad$ transmission length of the prestressing strand (m)

* Division of Structural Engineering, Concrete Structures, Chalmers University of Technology, SE-412 96 Göteborg, Sweden.

(MCR 41353) Paper received 22 December 2004; accepted 21 April 2005 . $l_{x} \quad$ distance between the section studied and the starting point of the transmission length $(\mathrm{m})$

$M \quad$ imposed moment $(\mathrm{Nm})$

$P \quad$ prestressing force $(\mathrm{Pa})$

$S \quad$ first moment of area above and around the centroidal axis $\left(\mathrm{m}^{3}\right)$

$T \quad$ applied torsional moment (Nm)

$T_{R, \text { top }} \quad$ torsional capacity for the top flange $(\mathrm{Nm})$

$T_{R \text {,web }}$ torsional capacity for the outermost web $(\mathrm{Nm})$

$t \quad$ thickness (m)

$t_{\text {bottom }}$ thickness of the bottom flange (m)

$t_{\text {top }} \quad$ thickness of the top flange (m)

$u$ outer circumference of the transformed crosssection $(\mathrm{m})$

$V \quad$ applied shear force $(\mathrm{N})$

$V_{R, \mathrm{c}} \quad$ shear capacity $(\mathrm{N})$

$V_{R \mathrm{~d}, \mathrm{c}} \quad$ design value of shear capacity $(\mathrm{N})$, given in EN 1168

$V_{R \mathrm{dn}} \quad$ design value of the shear capacity for simultaneous torsion $(\mathrm{N})$, given in EN 1168

$V_{R \mathrm{n}} \quad$ shear capacity for simultaneous torsion

$V_{E T d}$ design value of acting shear force in the web owing to torsion $(\mathrm{N})$, given in EN 1168

$V_{\mathrm{T}} \quad$ shear force in the web owing to torsion (N)

$W_{\mathrm{t}} \quad$ sectional modulus for torsion $\left(\mathrm{m}^{3}\right)$ 


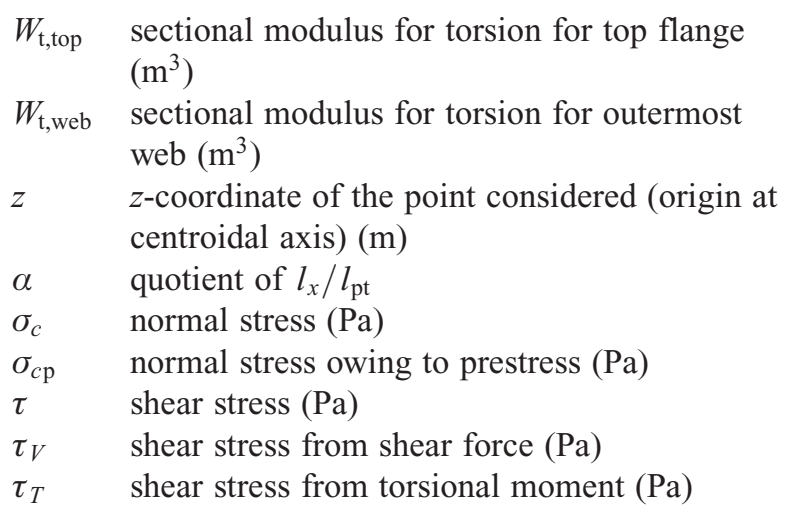

\section{Introduction}

The use of precast prestressed hollow core units for floors is common in all kinds of buildings, especially where large spans are required. The hollow core units are designed mainly to resist bending moment and shear: owing to the production methods, there is no transverse or vertical reinforcement. This, in combination with the prestress and the cross-section geometry, with large voids to save material and reduce selfweight, makes the units sensitive to shear and torsion. There are, however, many applications in which hollow core units are subjected to combined shear and torsion, for example in floors supported on three edges, in floors with openings and in floors with skew ends.

A significant amount of research has been done on shear in hollow core units. The shear strength has been investigated experimentally, analytically, or both by Walraven and Mercx, ${ }^{1}$ Pisanty, ${ }^{2}$ Yang, ${ }^{3}$ Jonsson, ${ }^{4}$ Hoang, ${ }^{5}$ Becker and Buettner ${ }^{6}$ and, in combination with flexible supports, also by Pajari. ${ }^{7,8}$ Procedures for predicting the shear capacity have been presented by Walraven and Mercx, ${ }^{1}$ Pisanty, ${ }^{2}$ Yang $^{3}$ and Hoang 5 . The combination of shear and torsion in hollow core units is, however, not so well investigated. To the authors' knowledge, the publication by Gabrielsson, ${ }^{9}$ who focused on experiments and analytical modelling of eccentrically loaded hollow core units, and the work done within this project, by Pajari ${ }^{10,11}$ and by the authors, ${ }^{12-14}$ are the only pieces of work dealing with this subject.

Torsion on a hollow core unit generates shear stresses that act mainly in the perimetric zone. In the outermost webs, these stresses act upwards in one and downwards in the other. A vertical shear force, on the other hand, produces shear stresses that are uniformly distributed over all webs. When vertical shear and torsion act simultaneously on one hollow core unit, the stresses from these influences interact. This means that one of the outermost webs in the cross-section receives much higher stresses than the others. The current calculation method for shear and torsion in EN 1168, ${ }^{15}$ adds stresses from shear and from torsion linearly, without taking into account deformations and compatibility within the hol- low core unit. Earlier research indicates, however, that there is a redistribution within the hollow core unit. ${ }^{9,10,12,13,15}$

To improve the current knowledge and understanding of shear and torsion interaction in hollow core floors, a European research project called Holcotors was started in January 2002. The aim of the project is to develop an improved design procedure for shear and torsion interaction in hollow core floors. To reach this goal, experiments were combined with finite element (FE) analyses, using non-linear fracture mechanics, for hollow core units as well as for whole floors.

The aim of the analyses reported here is to evaluate the load-carrying capacity and the response of the hollow core units investigated when they are subjected to various combinations of shear and torsion. An additional goal is to establish shear and torsion interaction diagrams that could be used in practical design when the shear force and torsional moment are given.

In a previous part of the project, three-dimensional FE models of $200 \mathrm{~mm}$ and $400 \mathrm{~mm}$ thick hollow core units were developed and validated by full-scale tests. ${ }^{13}$ This paper analyses similar FE models for several load combinations with various ratios of shear and torsion, from pure torsion to pure shear. One of the load combinations was validated against full-scale experiments done within the project at VTT, Technical Research Centre of Finland. ${ }^{10}$ Moreover, the effects of the shear span and the influence of the prestressing transfer zone on the shear and torsion capacity were evaluated. Finally, the interaction diagrams obtained from the FE analyses are compared with the analytical model in EN 1168.

\section{Analytical method}

The possible failure modes for simply supported hollow core units have been summarised. ${ }^{1,16}$ As regards the behaviour for loading close to the support, the following failure modes are distinguished. The failure could start by a flexural crack that becomes an inclined shear crack and results in failure either by crushing or splitting of the compression zone or by shear sliding along the inclined crack. A flexural crack close to the support could result in failure owing to slipping of the strands. Another possible failure mode is shear tension failure that occurs in regions not cracked in bending; this starts in the webs with an inclined crack, which propagates both upwards and downwards until failure. A hollow core unit subjected to torsion could start cracking in the top flange, in the bottom flange or in one of the outermost webs. Whether this cracking results in failure or not depends on the possible redistribution of the stresses.

\section{Shear}

In a prestressed hollow core cross-section subjected to vertical shear, it is assumed that the shear stresses 
produced are uniformly distributed over all webs. A shear tension crack is formed when the principal tensile stress in the concrete reaches a critical value, that is the concrete tensile strength, $f_{\text {ct }}$. Thus, cracks usually form, according to Walraven and Mercx, ${ }^{1}$ where the plane inclined at $45^{\circ}$ from the edge of the support intersects with the mid-depth plane, see Fig. 1. Here the prestressing force is not fully developed and the web width is at a minimum. In the critical section the normal stress, $\sigma_{c}$, owing to the pre-stressing and bending moment, and shear stress, $\tau_{V}$, owing to vertical shear, are superimposed. The normal stress can be estimated as

$$
\sigma_{c}(z)=\frac{-\alpha P}{A_{\mathrm{c}}}+\frac{-\alpha P e+M}{I_{c}} z
$$

where $\mathrm{P}$ is the prestressing force, $\alpha=1_{x} / 1_{\mathrm{pt}} \leqslant 1$ where $l_{x}$ is the distance between the section considered and the starting point of the transmission length, and $l_{\mathrm{pt}}$ is the transmission length of the prestressing strand. Here, $A_{\mathrm{c}}$ is the cross-sectional area, $e$ is the eccentricity of the strands, $z$ is the $z$-coordinate of the point considered (origin at centroidal axis), $M$ is the imposed moment and $I_{c}$ is the second moment of area. The critical stress combination is, however, assumed to be in a section at mid-depth $(z \approx 0)$ and, therefore, it is independent of the flexural moment.

$$
\sigma_{c}(0)=\frac{-\alpha P}{A_{\mathrm{c}}}=-\alpha \sigma_{\mathrm{cp}}
$$

Theoretically, therefore, if the shear force is constant between the support and the load, the shear capacity is independent of the shear span. The shear stress owing to load is

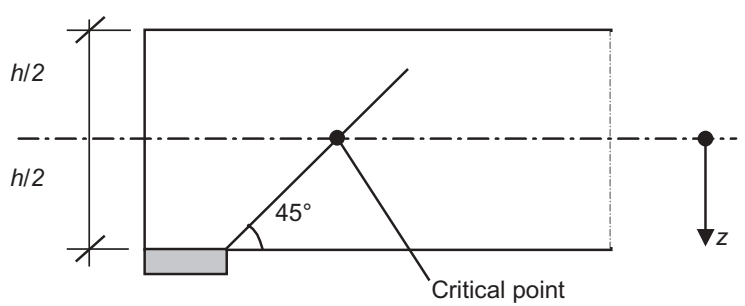

Fig. 1. Most probable point for a shear tension crack to start

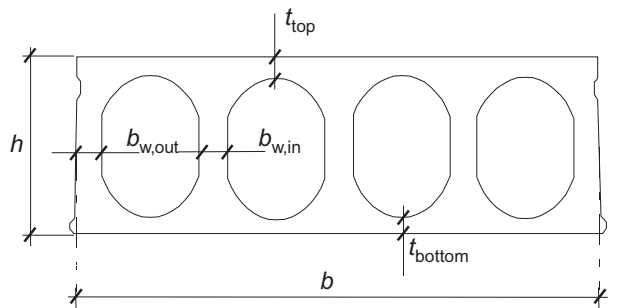

$$
\tau_{V}=\frac{V S}{\sum b_{\mathrm{w}} I}
$$

where $V$ is the applied shear force, $S$ is the first moment of area above and around the centroidal axis and $\sum b_{\mathrm{w}}$ is the sum of the widths at the centroidal axis of all webs.

In the ultimate limit state, the principal tensile stress is equal to the tensile strength of the concrete, and thus

$$
f_{\mathrm{ct}}=\frac{\sigma_{c}}{2}+\sqrt{\left[\left(\frac{\sigma_{c}}{2}\right)^{2}+\tau^{2}\right]}
$$

Then, with $\tau=\tau_{V}$ and by inserting equations (2) and (3) into equation (4) and assuming that cracking results in failure, it follows that the shear capacity for web shear tension failure can be estimated as

$$
V_{R, \mathrm{c}}=\frac{I \sum b_{\mathrm{w}}}{S} \sqrt{ }\left(f_{\mathrm{ct}}^{2}+\alpha \sigma_{\mathrm{cp}} f_{\mathrm{ct}}\right)
$$

This formula corresponds to the formula for shear capacity, $V_{R \mathrm{~d}, \mathrm{c}}$, given in EN 1168.

\section{Torsion}

The torsional loading causes shear stresses, $\tau_{T}$, acting mainly in the perimetric zone of the cross-section. In the outermost webs and in the flanges, these stresses act together with the normal stresses, $\sigma_{c}$, introduced by the prestressing and by the bending moment. The actual stress combination and the thickness of the flanges and the outermost webs determine whether the cracking starts in a web or in one of the flanges. The shear stress owing to torsion is calculated as

$$
\tau_{T}=\frac{T}{W_{\mathrm{t}}}
$$

where $W_{\mathrm{t}}$ can be calculated by transforming the crosssection of the hollow core unit into a tubular crosssection, see Fig. 2

$$
W_{\mathrm{t}}=2 t\left[h-\frac{\left(t_{\text {top }}+t_{\text {bottom }}\right)}{2}\right]\left(b-b_{\mathrm{w}, \text { out }}\right)
$$

where $t=t_{\text {top }}$ in calculations for the top flange and $t=$ $b_{\mathrm{w}, \text { out }}$ in those for the outermost web. However, the thickness, $t$, may not be larger than $A / u$, where $A$ is the total cross-sectional area (including inner hollow areas)

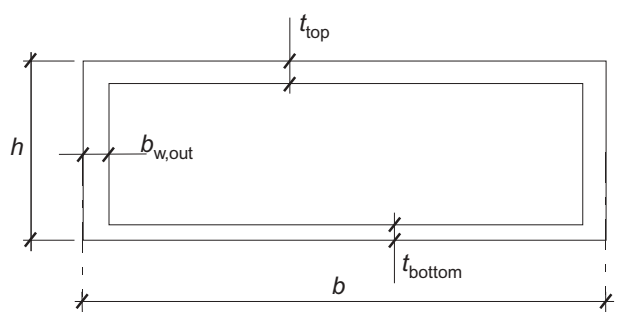

Fig. 2. The cross-section of one hollow core unit transformed into a tubular cross-section for calculations of the torsional resistance 
and $u$ is the outer circumference of the transformed cross-section.

In the ultimate limit state the tensile strength again limits the tensile stresses. Accordingly, by inserting $\tau_{T}$ as $\tau$ in equation (4) and combining it with equation (6), the torsion capacity, assuming that cracking of the top flange results in failure, is

$$
T_{R, \text { top }}=W_{\mathrm{t}, \text { top }} \sqrt{ }\left(f_{\mathrm{ct}}^{2}+\sigma_{c} f_{\mathrm{ct}}\right)
$$

and the torsion capacity assuming that cracking in the outermost web results in failure is

$$
T_{R, \mathrm{web}}=W_{\mathrm{t}, \mathrm{web}} \sqrt{ }\left(f_{\mathrm{ct}}^{2}+\alpha \sigma_{c \mathrm{p}} f_{\mathrm{ct}}\right)
$$

\section{Shear and torsion}

For a component loaded simultaneously with vertical shear and torsion, the shear stresses from each action are added in one of the outermost webs

$$
\tau=\tau_{V}+\tau_{T}
$$

by including $\tau_{V}$ from equation (3) and $\tau_{T}$ from equations (6) and (7) calculated for $t=b_{\mathrm{w}, \text { out }}$. Thus, the shear stress in the outermost web is

$$
\tau=\frac{V S}{I \sum b_{\mathrm{w}}}+\frac{T}{b_{\mathrm{w}, \text { out }} 2\left(b-b_{\mathrm{w}, \mathrm{out}}\right)\left(h-\left(t_{\text {top }}+t_{\mathrm{bottom}}\right) / 2\right)}
$$

The shear capacity then becomes

$$
\begin{aligned}
V= & \frac{\tau I \sum b_{\mathrm{w}}}{S} \\
& -\frac{T \sum b_{\mathrm{w}} I}{b_{\mathrm{w}, \text { out }} 2\left(b-b_{\mathrm{w}, \text { out }}\right)\left(h-\left(t_{\mathrm{top}}+t_{\mathrm{bottom}}\right) / 2\right) S}
\end{aligned}
$$

By assuming that $I / S \approx d$ and $h$ - $\left(t_{\text {top }}+t_{\text {bottom }}\right) / 2 \approx d$, and identifying $V_{R, c}$ from equation (5), the reduced shear capacity for simultaneous torsion, assuming web shear tension failure at cracking, can be written as

$$
V_{R \mathrm{n}}=V_{R, \mathrm{c}}-\frac{T \sum b_{\mathrm{w}}}{b_{\mathrm{w}, \text { out }} 2\left(b-b_{\mathrm{w}, \mathrm{out}}\right)}=V_{R, \mathrm{c}}-V_{\mathrm{T}}
$$

where $V_{T}$ is the shear force in the web owing to torsion

$$
V_{\mathrm{T}}=\frac{T \sum b_{\mathrm{w}}}{b_{\mathrm{w}, \text { out }} 2\left(b-b_{\mathrm{w}, \text { out }}\right)}
$$

These equations correspond to the formulae for the net value of the shear capacity, $V_{R \mathrm{dn}}$, and the design value of acting shear force, $V_{E \mathrm{Td}}$, caused by the torsional moment given in EN 1168. ${ }^{15}$

As the shear stresses from shear and torsion are simply added together, there is a linear interaction between shear and torsion. According to the standard it is not necessary to check cross-sections closer to the support edge than half the height of the hollow core unit. It is worth noting that the method in EN $1168^{15}$ takes into account only the web shear tension failure of the outermost web: no other possible failure mode is considered to be critical.

\section{FE analyses}

This study investigates two geometries of hollow core units, the dimensions of which are shown in Fig. 3. One was a $200 \mathrm{~mm}$ thick unit with six circular voids and with seven prestressing strands in the bottom flange. The other was $400 \mathrm{~mm}$ thick, had four almost rectangular voids and was provided in the bottom flange with 11 prestressing strands. All strands were seven-wired with a diameter of $12.5 \mathrm{~mm}$. The initial prestress was $900 \mathrm{MPa}$ for the $200 \mathrm{~mm}$ thick units and $1000 \mathrm{MPa}$ for the $400 \mathrm{~mm}$ thick units.

In Broo et al. ${ }^{13}$ three-dimensional FE models of these two geometries of hollow core units were developed and validated by full-scale tests. Here, similar FE models, changed only with regard to support and loading conditions, were used for analyses of several load combinations with various shear-torsion ratios, from pure torsion to pure shear. All of the FE analyses described in this paper were made using the general FE program Diana, version $8 \cdot 1 \cdot 2 .{ }^{17}$ One of the load combinations was validated against full-scale experiments conducted at VTT. ${ }^{11}$

\section{FE analyses of full-scale tests}

The same test was made twice on the $400 \mathrm{~mm}$ thick hollow core unit, denoted ST400G1 and ST400G2. Fig. 4 shows the arrangements for these full-scale experiments. The torsion was applied by twisting one end of the hollow core unit and keeping the other end fixed. In the tests this was accomplished by allowing the support at one end to rotate around a longitudinal axle, and applying a point load at each support. For stability, the point loads had slightly different eccentricities in the transversal direction. A line load was applied with

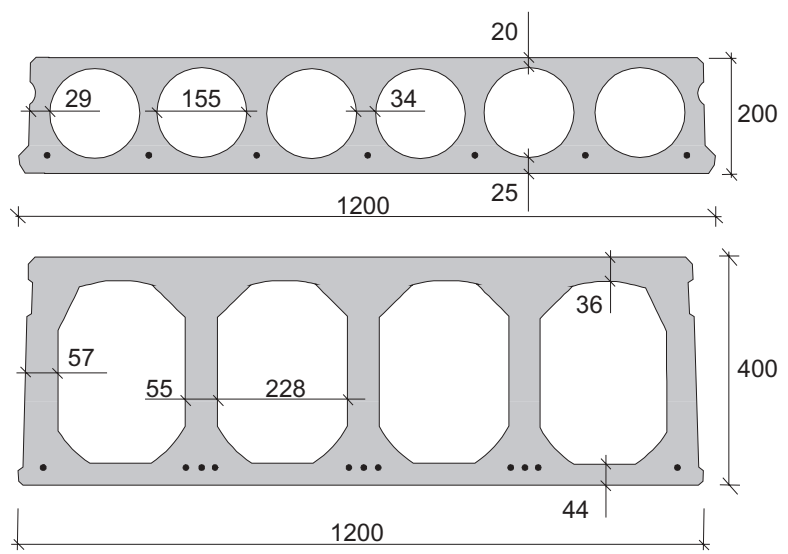

Fig. 3. Cross-sections of the hollow core units tested and analysed. Dimensions are given in $\mathrm{mm}$

Magazine of Concrete Research, 2005, 57, No. 9 


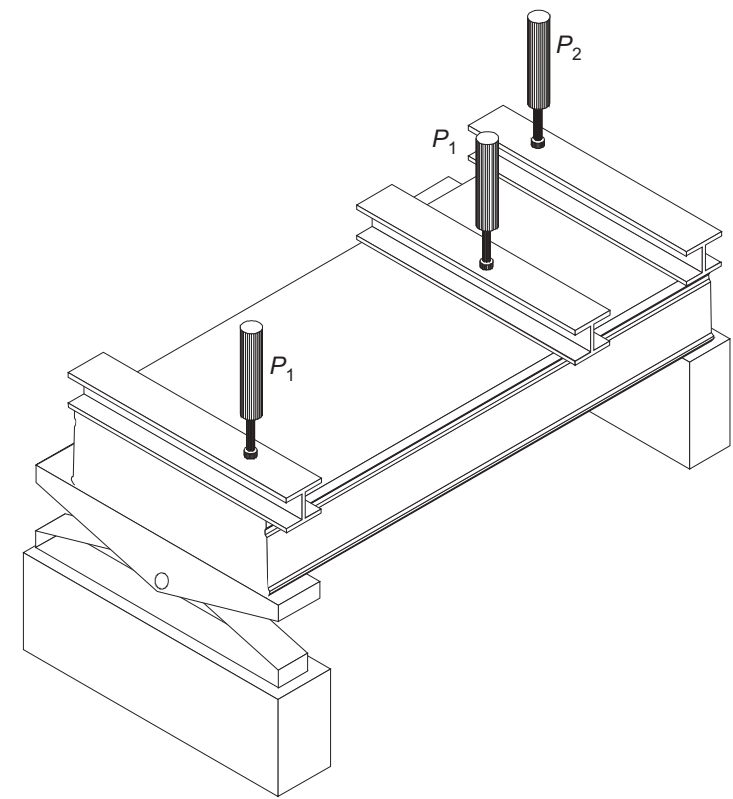

(a)

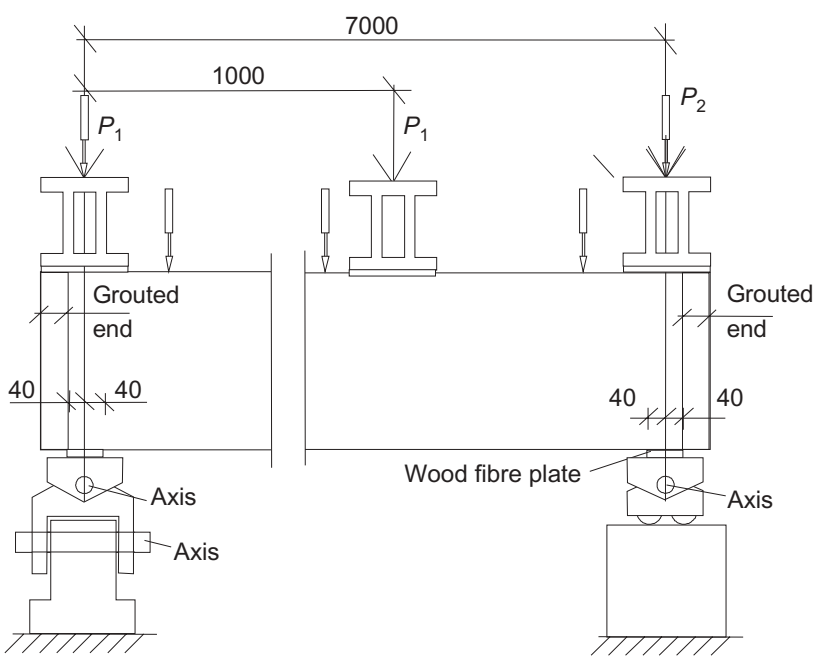

(b)

Fig. 4. Overview of test arrangements. Dimensions are given in mm. Modified from Pajari ${ }^{10}$

a shear span of $1.0 \mathrm{~m}$. The relation between shear and torsion was kept constant throughout the test.

Modelling technique. A sketch of the FE model used to analyse the $400 \mathrm{~mm}$ thick hollow core unit is given in Fig. 5. Eight-node solid elements were used only for the part of the hollow core unit where the failure was expected, close to the load in the span. The rest of the unit was modelled with three-node beam elements. The solid elements were connected to the beam elements by assuming a stiff rotation of the cross-section and that the plane cross-section remained plane. The beam elements were assigned the properties of a $400 \mathrm{~mm}$ high and $1200 \mathrm{~mm}$ wide hollow core unit by defining the cross-section with 17 zones, see Fig. 5(b). To obtain correct torsional stiffness of the beam elements, two factors, which TNO (the Netherlands Organisation for Applied Scientific Research) ${ }^{17}$ designates 'shear factors', were adjusted. The torsional stiffness was evaluated from pure torsion tests carried out within the project. ${ }^{11}$

In the analysis, the concrete was modelled with a constitutive model based on non-linear fracture mechanics. A rotating crack model based on total strain was used for the concrete. ${ }^{17}$ The hardening in compression was described by the expression suggested by Thorenfeldt; for the tension softening, the curve proposed by Hordijk was chosen, as described in TNO. ${ }^{17}$ Material data for the concrete were calculated from the compressive strength, evaluated from cylinder tests carried out by VTT, on $50 \mathrm{~mm}$ cores drilled from the test specimens, see Pajari. ${ }^{10}$ The mean tensile strength, $f_{\mathrm{ctm}}$, was calculated according to the Comité Euro-International du Béton $(\mathrm{CEB}),{ }^{18}$ the fracture energy, $G_{\mathrm{F}}$, and the
Young's modulus, $E_{\text {ci }}$, were calculated according to CEB. ${ }^{19}$ All material properties used for the concrete in the model are shown in Table 2 .

In the part with solid elements, the strands were modelled with two-node bar elements, combined with interface elements and a pre-defined bond-slip relation, to simulate the interaction between the prestressing steel and the concrete. The pre-defined bond-slip relationship between the seven-wire strands and the concrete was taken from pull-through tests carried out at Chalmers, by Lundgren, ${ }^{20}$ see Fig. 6. In the part of the model with beam elements, the strands were modelled as embedded reinforcement. This choice means that, in the beam elements, full interaction between the prestressing steel and the concrete was assumed. The constitutive behaviour of the prestressing steel was modelled by the von Mises yield criterion, with an associated flow law and isotropic hardening. For the analysis, the strength and modulus of elasticity measured in tensile tests carried out at VTT were used, see Pajari. ${ }^{10}$ The $0 \cdot 1 \%$ proof stress, $f_{\mathrm{p} 0 \cdot 1}$, was $1680 \mathrm{MPa}$, the ultimate tensile strength, $f_{\text {pu }}$, was $1910 \mathrm{MPa}$ and Young's modulus, $E_{\mathrm{p}}$, was $198 \mathrm{GPa}$.

In the analysis the torsion was applied by twisting the hollow core unit with eccentric point loads at the ends. At the end with beam elements, a stiff link was used, see C in Fig. 5(b), and at the end with solid elements, the eccentric point load was distributed over the whole width of the hollow core unit, see B in Fig. 5(b). The span was loaded with a centric point load that was also distributed over the whole width of the hollow core unit. In the tests the loads were distributed by $200 \mathrm{~mm}$ wide stiff steel beams. In the analysis this was simulated by tying the nodes of the loading area to the 

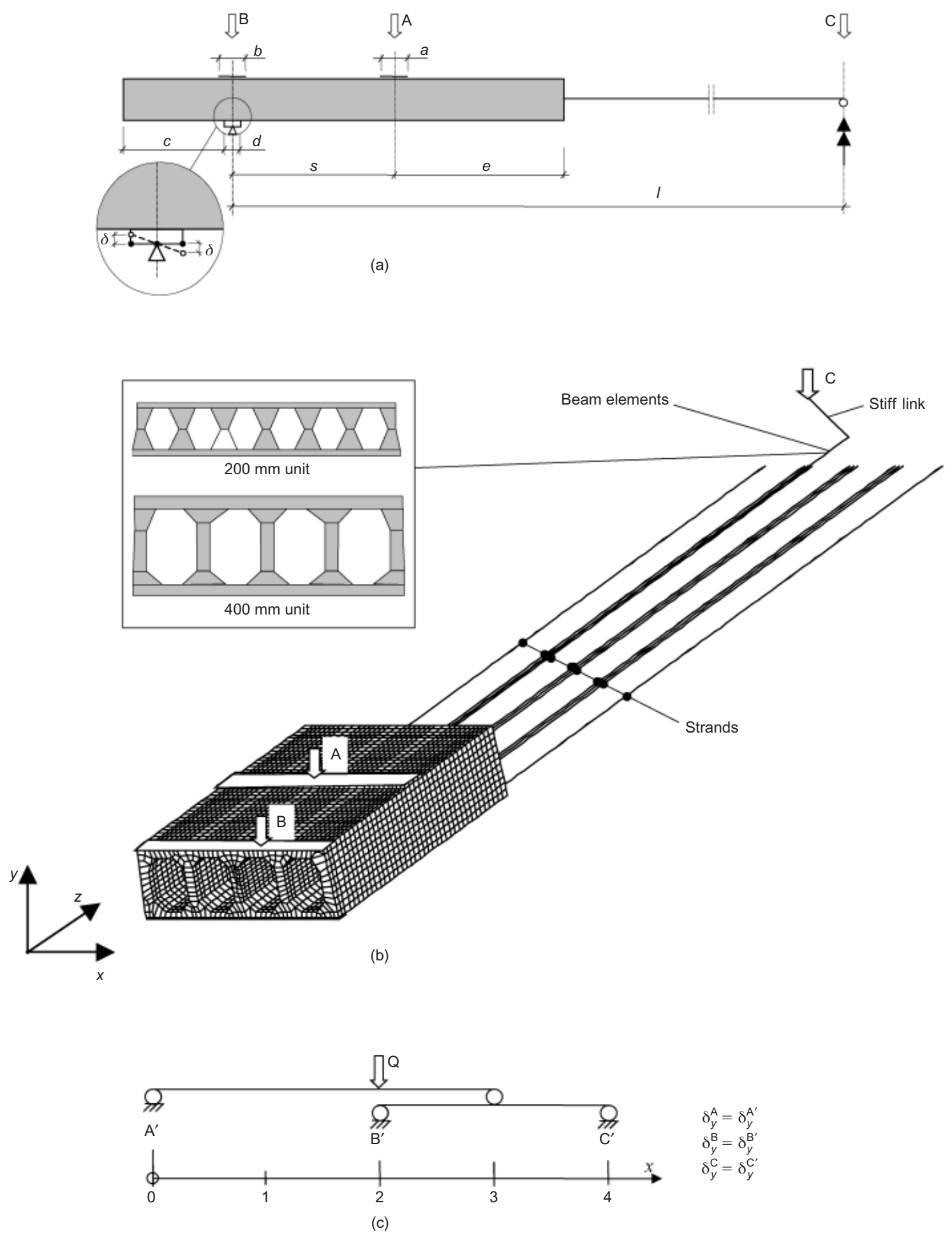

Fig. 5. (a) The principle of the FE models, see Table 1 for measurements; (b) FE model of the 400 mm thick unit, used to calculate the shear and torsion resistance; (c) loading arrangement of beams by which various combinations of shear end torsion were obtained by varying the position of the load $Q$

loaded node to keep this area in the vertical plan, see A in Fig. 5(b). In the analysis the load was distributed above the support over a $140 \mathrm{~mm}$ wide area. In the tests there were sheets of wood fibre between the unit and the steel beams. In the analysis these sheets of wood fibre were modelled with eight-node solid elements; full interaction was assumed between the concrete and the wood fibre. The tensile strength of the wood fibre was assumed to be $0.05 \mathrm{MPa}$, the Poisson ratio $v=0 \cdot 15$, Young's modulus $E=2 \mathrm{GPa}$, and the fracture energy $G_{\mathrm{F}}=10 \cdot 0 \mathrm{Nm} / \mathrm{m}^{2}$. For the tension softening, the curve proposed by Hordijk was chosen, as described in reference 17 .

In the tests the hollow core units were supported on Magazine of Concrete Research, 2005, 57, No. 9 


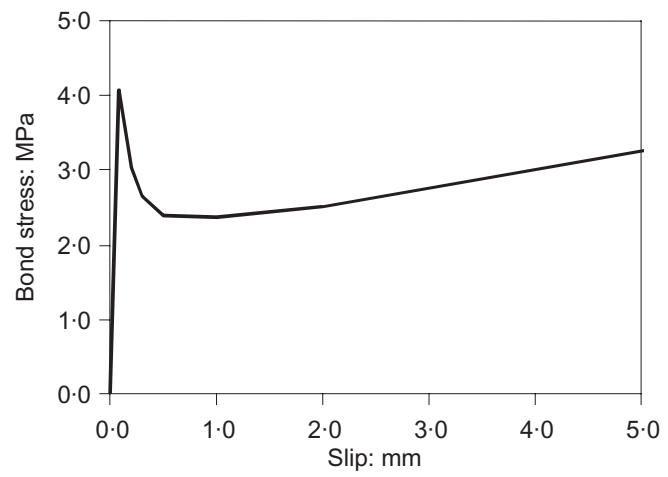

Fig. 6. Bond-slip relationship used between a seven-wire strand and concrete, from pull-through tests by Lundgren ${ }^{20}$

roller bearings. At each support there was a $10 \mathrm{~mm}$ thick sheet of wood fibre under the hollow core unit. In the analysis this sheet was modelled in the same way and had the same material properties as the sheet of wood fibre used under the steel beams. The nodes along the centre line of the modelled plate were supported vertically, transversally and longitudinally. The nodes at the edges were, however, tied to obtain the same vertical displacement, but in opposite directions, thus enabling a rotation and simulating a free support, see Fig. 5(a). In practice, and also in the tests, the end section of the hollow core units is grouted. To simulate this in the analysis, the nodes on the end cross-section were tied to keep the cross-section in plane and to have stiff rotation. In the analysis the end of the beam elements was supported for transversal and vertical displacement and for rotation around the vertical axis.

To enable deformation-controlled loading with a constant relation between shear and torsion, a separate loading arrangement of beams was modelled, see Fig. 5(c). The loading beams were modelled with three-node beam elements that have the properties of stiff beams without dead weight. The beams were supported as shown in Fig. 5(c). The nodes where loads were applied on the hollow core unit (A, B and C) in Fig. 5(b) were tied so they would have the same vertical displacement as the supporting nodes $\left(\mathrm{A}^{\prime}, \mathrm{B}^{\prime}\right.$ and $\left.\mathrm{C}^{\prime}\right)$ in Fig. 5(c) on the loading arrangement. The hollow core unit could be loaded by applying $Q$ anywhere along the $x$-axis on the loading beam; $x=0 \mathrm{~m}$ for pure shear and $x=3.0 \mathrm{~m}$ for pure torsion. In this analysis the load, $Q$, was posi- tioned at $x=2.0 \mathrm{~m}$ to obtain the same ratio of shear and torsion as in the full-scale experiments.

Deformation-controlled analysis had to be carried out in two phases. In the first phase, the loading beam arrangement was not active; then the prestressing force was released and the self-weight was applied. In the second phase, all of the elements were active. Owing to the syntax of the program, the self-weight had to be applied again. Thereafter, the loading was applied by increasing the vertical displacement of the chosen node $(x=2.0 \mathrm{~m})$ along the loading beam.

Results. The load versus vertical displacement from the tests is compared with FE analysis results in Fig. 7. In both tests the first crack was an inclined flexural crack below the loading point at a load of approximately $Q=300 \mathrm{kN}$. After the load dropped slightly, it could be increased until failure at $Q=$ $334 \mathrm{kN}$ for ST400G1 and $Q=357 \mathrm{kN}$ for ST400G2. In the analysis there were no cracks before failure at a load of $Q=356 \mathrm{kN}$. In Fig. 8 the crack pattern from the tests and the analysis are shown. Although the load versus vertical displacement relation for the two tests was similar and the capacities were almost the same, the crack patterns did not reveal the same failure modes. The ST400G1 test failed in web shear tension, see Fig. 8(a). For the ST400G2 test, however, the failure mode was not completely clear, see Fig. 8(b). Pajari classifies it as a shear-torsion anchorage failure. ${ }^{10}$ In the analysis of the tests, the crack pattern

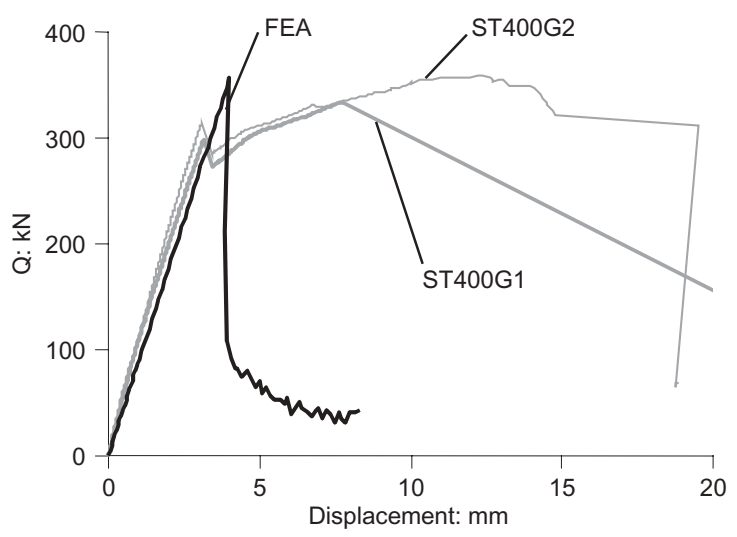

Fig. 7. Load versus displacement: comparison of FE analysis and test

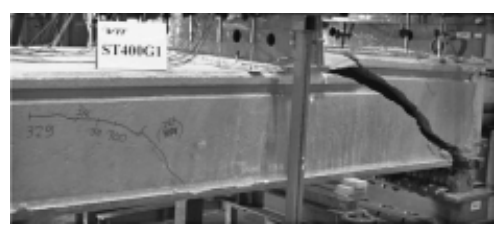

(a)

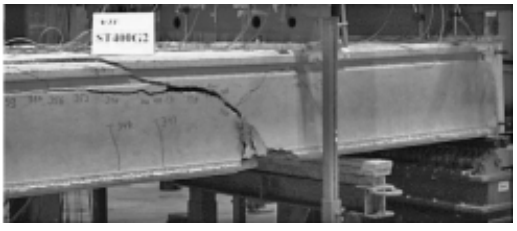

(b)

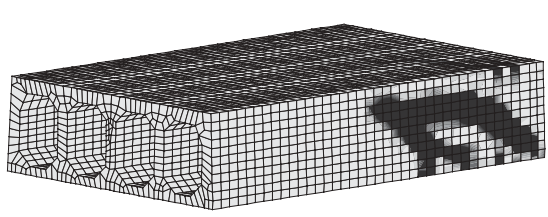

(c)

Fig. 8. Crack pattern from tests: (a) ST400G1; (b) ST400G2; (c) the corresponding FE analysis 
as shown in Fig. 8(c), indicated a web shear tension failure.

\section{FE analyses for shear and torsion interaction diagrams}

FE analyses for several load cases with different relations between shear and torsion were made for both the $200 \mathrm{~mm}$ and the $400 \mathrm{~mm}$ thick hollow core units to establish shear and torsion interaction diagrams. To evaluate the effects of shear span and the influence of the prestressing transfer zone on the shear and torsion capacities, three set-ups were analysed for the $200 \mathrm{~mm}$ thick hollow core unit, see Fig. 5(a). In Table 1 the measurements for the set-ups are given. Two set-ups had the prestress transfer region inside the shear span: the shear spans were $0.8 \mathrm{~m}$ and $0.5 \mathrm{~m}$, denoted VT2IN-0.8 and VT2-IN-0.5. The third set-up, denoted VT2OUT- $0 \cdot 8$, had the transfer region outside the shear span of $0.8 \mathrm{~m}$. For the $400 \mathrm{~mm}$ thick unit, the shear span chosen was $1.0 \mathrm{~m}$ for the set-up with the transfer region inside the shear span, VT4-IN-1.0, as well as for the set-up with the transfer region outside the shear span, VT4-OUT-1.0. To have the prestress transfer region outside the shear span, one end of the hollow core units was cantilevered $1.0 \mathrm{~m}$ from the support at the loaded end.

Modelling technique. To analyse the $400 \mathrm{~mm}$ thick hollow core unit, principally the same FE model as in the analysis of the tests was used. The mesh for the analyses of the $200 \mathrm{~mm}$ thick units was established by the same principle. The width of the loading area, see A in Fig. 5, was half of the thickness of the hollow core unit. In these analyses, the loading area over the support, see B in Fig. 5, had the same width as the support. The sheets of wood fibre at these places were not included. The concrete compressive strength used here was a mean value from all of the tests on each of the geometries included in this project. ${ }^{10}$ All material properties used for the concrete in the models are shown in Table 2. For all other material properties the same values were used as in the analysis of the tests.

The separate loading arrangement of beams made it possible easily to vary the relation between shear and torsion. This was done in the analyses to establish the interaction curves. For all set-ups, an analysis was made for each ratio of shear and torsion chosen. In total, 57 analyses were made.

Results. With results from FE analyses, it was possible to establish shear and torsion interaction diagrams for the geometries investigated, see Figs 9-11. Each solid mark in the diagrams is the result from one analysis: the actual shear force and the torsional moment are calculated for the maximum load. The open marks with dashed curves show the shear force and torsional moment from the analyses when it was estimated that the first crack would be visually observed in a corresponding test.

Figure 9 shows the interaction diagram for VT4-IN1.0. For some load combinations, the crack pattern just after the maximum load is shown. In the diagram the results from the two tests, ST400G1 and ST400G2, are also included. The diagram shows that the interaction between shear and torsion is non-linear. The failure mode changed gradually with the shear-torsion ratio. As can be seen from the crack patterns, the failure mode varied from a diagonal crack in the upper flange for combinations close to pure torsion, to shear tension cracks in the webs and also bending cracks in the bottom flange, for combinations close to pure shear. When the shear force is less than approximately $200 \mathrm{kN}$, the curve is almost horizontal and the torsional capacity is not affected by the increased shear force.

Table 1. Measurements for the set-ups. Notation as shown in Fig. 5(a)

\begin{tabular}{l|c|c|c|c|c|c}
\hline Identification & ST4G & VT4-IN-1.0 & VT4-OUT-1·0 & VT2-IN-0.8 & VT2-IN-0.5 & VT2-OUT-0.8 \\
\hline Shear span $(s): \mathrm{m}$ & $1 \cdot 0$ & $1 \cdot 0$ & $1 \cdot 00$ & 0.80 & 0.50 & 0.80 \\
Cantilever $(c): \mathrm{m}$ & - & - & $0 \cdot 96$ & - & - & $0 \cdot 97$ \\
Extension $(e): \mathrm{m}$ & $0 \cdot 9$ & $0 \cdot 9$ & $0 \cdot 90$ & $0 \cdot 75$ & $0 \cdot 75$ & $0 \cdot 75$ \\
Support length $(d): \mathrm{mm}$ & 80 & 80 & 80 & 60 & 60 & 60 \\
Loading plate A $(a): \mathrm{mm}$ & 200 & 200 & 200 & 100 & 100 & 100 \\
Loading plate B $(b): \mathrm{mm}$ & 140 & 80 & 80 & 60 & 60 & 60 \\
\hline
\end{tabular}

Table 2. Material properties used for the concrete in the FE analyses

\begin{tabular}{l|c|c|c|c|c}
\hline & $\begin{array}{c}\text { Mean concrete } \\
\text { compressive strength } \\
f_{c \mathrm{~cm}}: \mathrm{MPa}\end{array}$ & $\begin{array}{c}\text { Mean concrete tensile } \\
\text { strength } f_{c \text { tm }}: \mathrm{MPa}\end{array}$ & $\begin{array}{c}\text { Fracture energy } G_{\mathrm{F}}: \\
\mathrm{Nm} / \mathrm{m}^{2}\end{array}$ & $\begin{array}{c}\text { Young's modulus of } \\
\text { concrete } E_{c i}: \mathrm{GPa}\end{array}$ & $\begin{array}{c}\text { Shear factors [-] } \\
\text { (beam elements only) }\end{array}$ \\
\hline ST4G & $61 \cdot 2$ & $3 \cdot 75$ & $106 \cdot 6$ & $39 \cdot 33$ & $4 \cdot 06$ \\
VT4 & 61.0 & $3 \cdot 74$ & $106 \cdot 3$ & $39 \cdot 28$ & $4 \cdot 06$ \\
VT2 & $53 \cdot 2$ & $3 \cdot 45$ & $88 \cdot 7$ & 37.54 & $10 \cdot 39$ \\
\hline
\end{tabular}


(c)

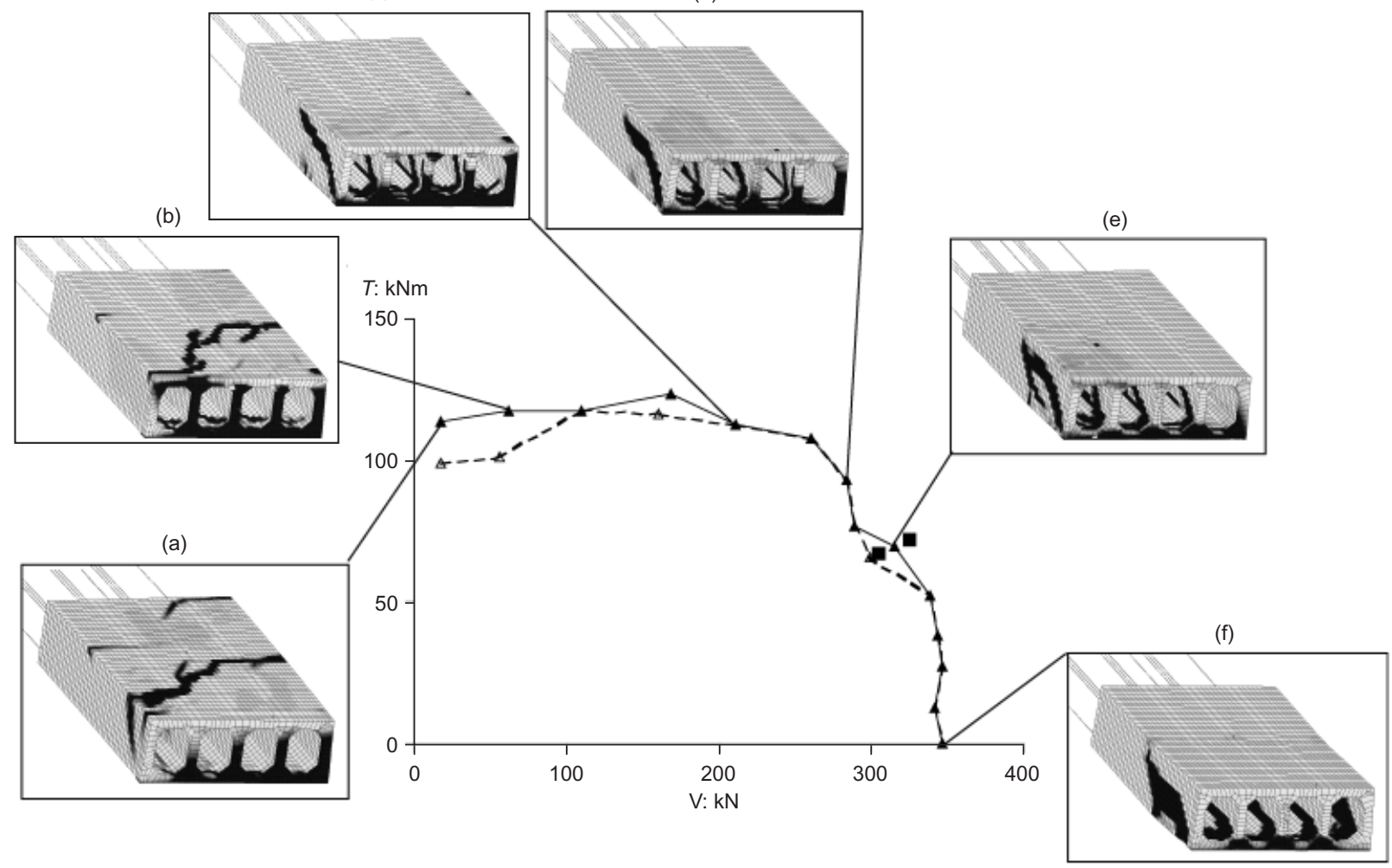

Fig. 9. Shear and torsion interaction diagram for the $400 \mathrm{~mm}$ thick hollow core unit with the prestress transfer region within the shear span, VT4-IN-1·0. Each solid mark is the result from one analysis: the shear force and torsional moment are calculated at the maximum load. The open marks with dashed curves show the shear force and torsional moment when it was estimated that the first crack would be visually observed in a corresponding test. (a)-(f) Crack pattern just after maximum load for some load combinations

Nevertheless, the crack patterns show that the relations between shear and torsion affect the failure modes. For some combinations, as the dashed curve shows, cracks were observed before the maximum load was reached in the analyses. This indicates some stress redistribution. For combinations with a shear capacity less than $200 \mathrm{kN}$, these cracks were observed in the top flange. For the combination shear/torsion $\approx 300 / 70$, the crack was observed in the second web.

The interaction diagram for VT4-OUT-1.0 is shown in Fig. 10 together with the crack pattern just after the maximum load from some of the analyses. Outside the transfer region the prestress is fully developed; this explains why the capacities are higher than in the previous diagram. For a shear force less than approximately $200 \mathrm{kN}$, the capacity for torsional moment increases with the shear force. This is the result of increased bending moment and, therefore, the tensile stresses in the top flange decrease and a higher torsional moment can be carried. These stresses, in combination with the thickness of the top flange and the outermost webs, will determine if the failure starts in the web or in the top flange, see equations (8) and (9). As long as the critical point for failure is in the top flange the decrease of tensile stresses owing to in- creased bending moment will lead to a higher capacity for torsional moment, see Figs 10 and 11. This line of argument is valid also for VT4-IN-1.0. The negative moment owing to the prestress is smaller within the anchorage region; the positive effects on the torsional capacity resulting from increased bending moment are, therefore, smaller, see Fig. 9. For all combinations with a torsional capacity higher than about $100 \mathrm{kN} / \mathrm{m}$, cracks in the top flange were visually observed before the maximum loads were reached. For the combination with pure shear and the one closest to it, flexural cracks in the bottom flange were observed before the maximum load. After the maximum load was reached, however, shear tension cracks occurred in the webs.

Figure 11 shows the interaction diagram for VT2-IN0.5 and VT2-IN-0.8. As can be seen, the capacity was higher when the load was applied closer to the support. This indicates that the failure is affected by the loading arrangement. It is hard (nearly impossible) to predict a shear capacity that is not affected by the boundaries. For a shear force less than approximately $50 \mathrm{kN}$, the capacity for torsional moment increases with the shear force, owing to increased bending moment. Cracks were observed before the maximum loads were reached for several combinations. For combinations with tor- 


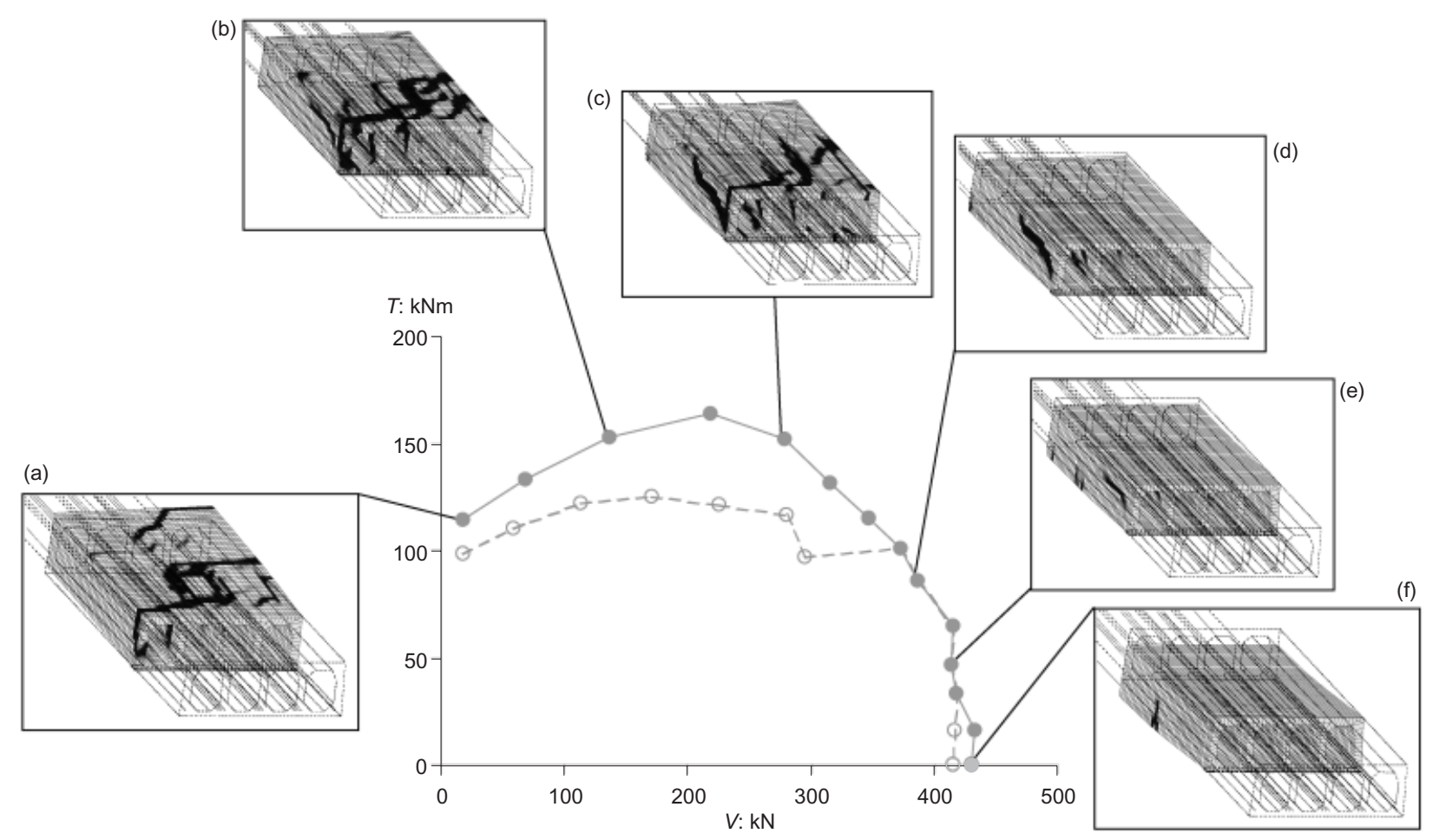

Fig. 10. Shear and torsion interaction diagram for the $400 \mathrm{~mm}$ thick hollow core unit with the prestress transfer region outside the shear span, VT4-OUT-1·0. Each solid mark is the result from one analysis: the shear force and torsional moment are calculated for the maximum load. The open marks with dashed curves show the shear force and torsional moment when it was estimated that the first crack would be visually observed in a corresponding test (a)-(f) Crack pattern just after maximum load for some load combination

sional capacity higher than $30 \mathrm{kN} / \mathrm{m}$, these cracks were observed in the top flange, marked with open circles in Fig. 11. For the combinations marked with open diamonds, flexural cracks in the bottom flange were observed before or at the maximum load. In combination with large slips of the strands and no cracks in the webs after maximum load, see Fig. 11 (i) and (j), this indicates anchorage failures. The shear and torsion capacity were thus obtained by anchorage failure, not by a web shear tension failure.

\section{Comparison of FE analyses and the analytical method}

The capacities from the FE analyses are compared with those predicted by the formulae given in the present standard, EN 1168, ${ }^{15}$ in shear and torsion interaction diagrams, see Figs 12 and 13. The same mean tensile strength as in the FE analyses was used in the calculations, that is the mean tensile strength calculated according $\mathrm{CEB},{ }^{18}$ which gives a slightly lower tensile strength than EN1992. ${ }^{21}$ Altogether the FEA results from various combinations of shear and torsion gave non-linear convex interaction curves compared with the linear relation given in EN 1168, see equation (13). As can be seen, the FE analyses gave higher capacity than the method in EN 1168 for most combinations of shear and torsion, both for the $200 \mathrm{~mm}$ and the $400 \mathrm{~mm}$ thick hollow core unit. The increase in capacity is large when the transfer region is inside the shear span (IN) as well as outside (OUT) the shear span, up to $55 \%$ and $30 \%$, respectively, for the $200 \mathrm{~mm}$ thick hollow core unit, Fig. 12. For the $400 \mathrm{~mm}$ thick hollow core unit, Fig. 13, the increase is up to $30 \%$ when the transfer region is inside the shear span and up to $25 \%$ when it is outside.

As the prevailing stresses owing to the prestressing are of great importance for where the failure starts, the transmission lengths resulting from the FE analyses are compared with those calculated with the method in the standard, see Fig. 14. In the FE analyses, no adjustment of the initial prestress was made to account for relaxation, creep or shrinkage. After release of the prestressing force, the resulting steel stress in the FE analyses of the $200 \mathrm{~mm}$ thick hollow core units was $855 \mathrm{MPa}$ and $946 \mathrm{MPa}$ for the $400 \mathrm{~mm}$ thick units; the strands were fully anchored within approximately $0.8 \mathrm{~m}$ and $0.9 \mathrm{~m}$, respectively. The hand calculations of the anchorage length were made by assuming that the hollow core units were sawn (release of prestressing force) one day after grouting; the initial prestressing level was reduced by $50 \mathrm{MPa}$. The resulting anchorage length was $0.69 \mathrm{~m}$ for the $200 \mathrm{~mm}$ thick units and $0.80 \mathrm{~m}$ for the $400 \mathrm{~mm}$ thick units. The small differences in trans- 


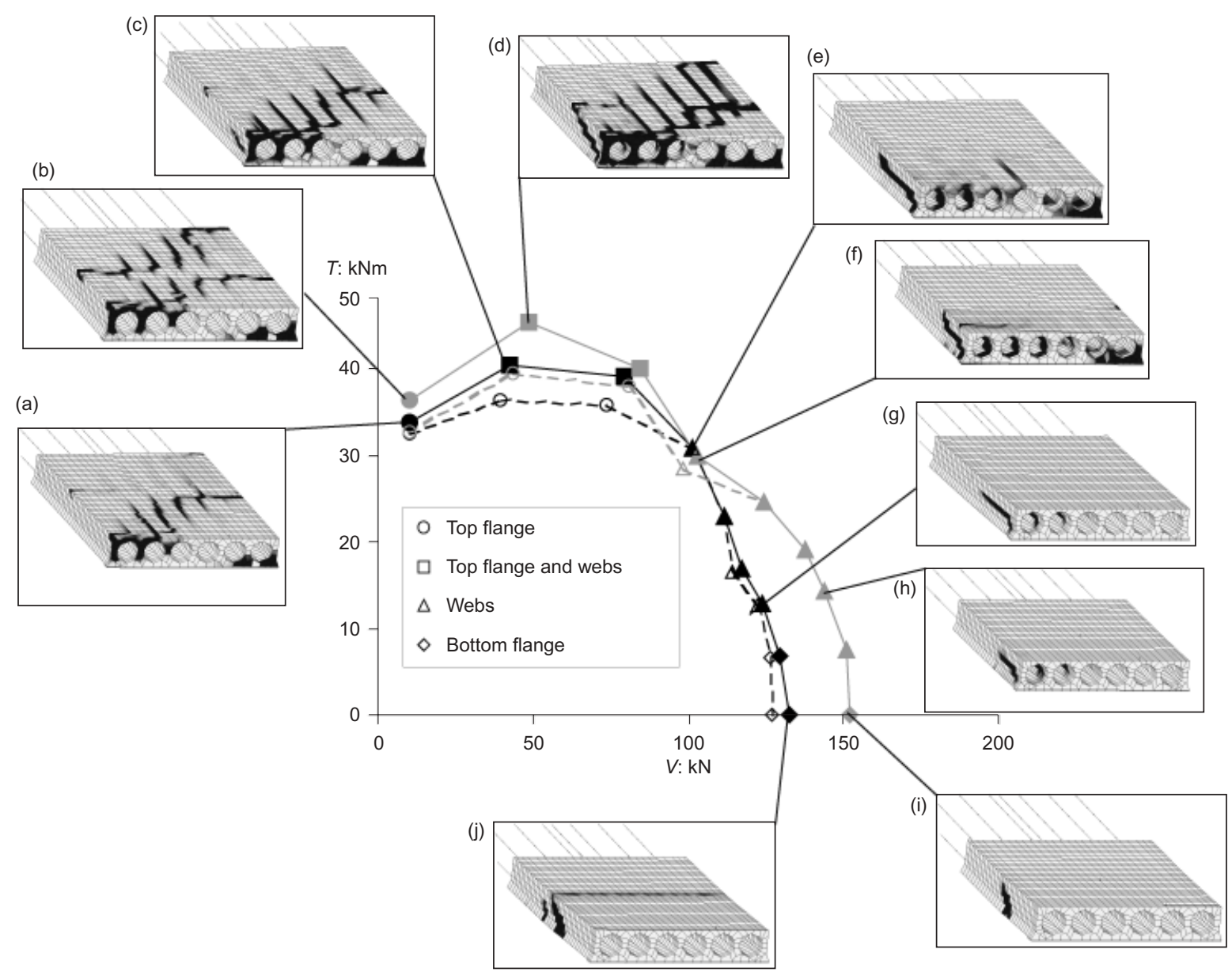

Fig. 11. Shear and torsion interaction diagrams for the $200 \mathrm{~mm}$ thick hollow core unit with the prestress transfer region within the shear span: black for shear span $0.8 \mathrm{~m}$ and grey for shear span $0.5 \mathrm{~m}$. Each solid mark is the result from one analysis: the shear force and torsional moment calculated for the maximum load. The open marks with dashed curves show the shear force and torsional moment from the analyses when it was estimated that the first crack would be visually observed in a corresponding test. The marks show where cracks occurred. (a)-(j) Crack pattern just after maximum load for some load combinations

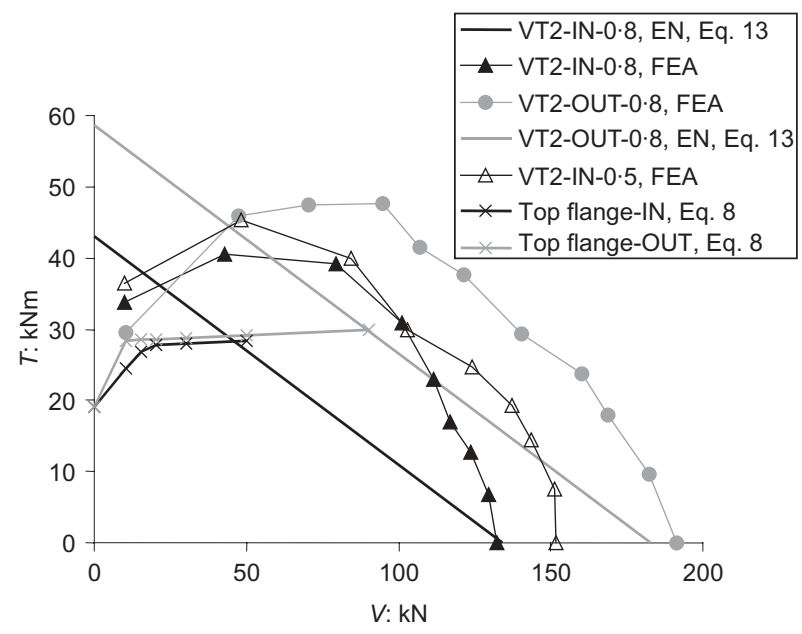

Fig. 12. Shear and torsion interaction diagram for the 200 mm thick unit

mission length cannot explain the higher capacities obtained in the FE analyses.

The FE analyses also showed that, for the crosssections studied, the method in EN $1168^{15}$ is not valid

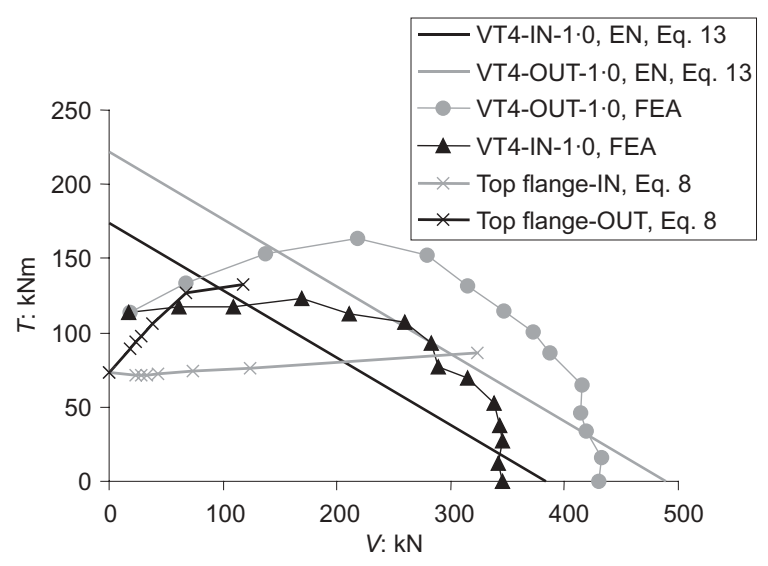

Fig. 13. Shear and torsion interaction diagram for the 400 mm thick unit

for loading close to pure torsion, where the failure took place in the upper flange of the hollow core unit. This failure mode is not taken into account in EN 1168; here, however, it has been calculated from equation (8) and included in the diagram. Note that, in the analytical 


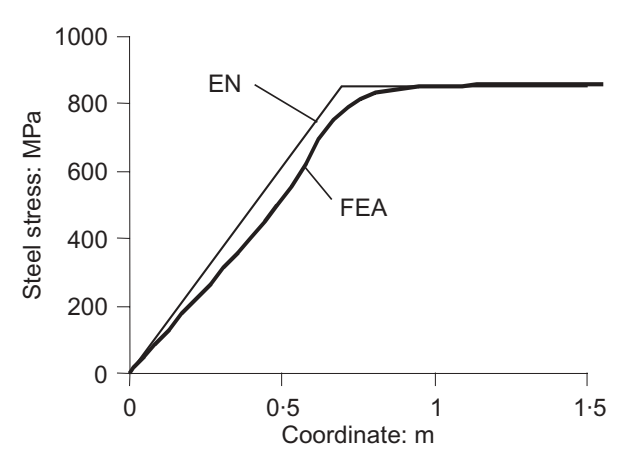

(a)

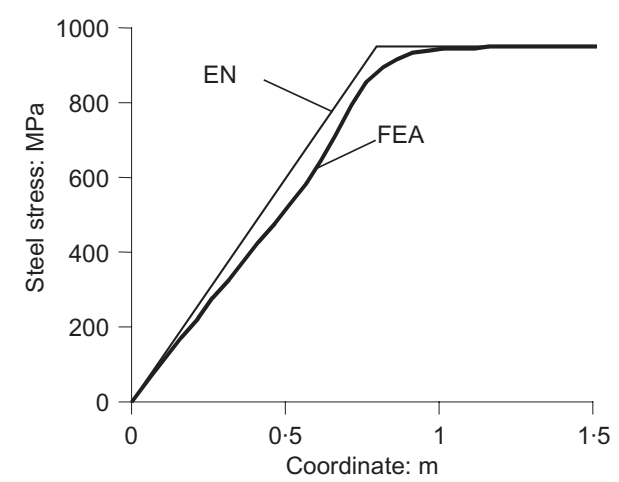

(b)

Fig. 14. Results from analysis compared with the predicted results, calculated by the method in EN 1168; steel stress in strands after release of prestressing force: (a) VT2; (b) VT4

model, the failure criterion is based on the crack load. The FE analyses showed, however, that after cracking in the upper flange, an additional load could be carried before failure occurred; hence, the structure could still be used owing to redistribution of stresses.

For the $400 \mathrm{~mm}$ thick hollow core unit, the method in EN 1168 slightly overestimates the capacity for pure shear. This difference may stem from the analytical model in which it is assumed that the cracking starts where the plane inclined at $45^{\circ}$, from the edge of the support, intersects with the mid-depth plane, see Fig. 1. At this intersection the prestressing force is not fully developed and, for cross-sections with circular voids, the web width is minimum; thus, this is the most critical section. This does not, however, seem to be true for cross-sections with constant web widths, ${ }^{3,7}$ as the critical section can be elsewhere than in the mid-depth plane, depending on the transfer of the prestress. Furthermore, the transfer of the prestressing force introduces not only compressive stress but also shear stresses in the structure, which influence the stress state in the webs. A calculation method to take this into account was proposed by Yang. ${ }^{3}$ In the FE analysis of the $400 \mathrm{~mm}$ thick unit subjected to pure shear, the shear tension crack starts in the middle web, lower than middepth and closer to the support than half the depth away (the critical point assumed in the analytical model), which is the same result obtained by Pajari. ${ }^{7}$

\section{Conclusions}

A method to use advanced non-linear FE analyses to obtain shear and torsion interaction diagrams is proposed. Two cross-sections were investigated: a $200 \mathrm{~mm}$ thick hollow core unit with six circular voids; and a $400 \mathrm{~mm}$ thick unit with four almost rectangular voids.

The FE analyses revealed a non-linear interaction between shear and torsion capacity in hollow core units rather than the linear one in EN $1168 .{ }^{15}$ Moreover, the FE analyses gave higher capacities than the calculation method in the present standard for almost all combinations of shear and torsion. The increase was up to $55 \%$ for the $200 \mathrm{~mm}$ thick unit and up to $30 \%$ for the $400 \mathrm{~mm}$ thick unit. For several of the combinations, cracks were visually observed in the FE analyses before the maximum load was reached; this indicates a redistribution of stresses.

For load situations close to pure torsion, the analyses resulted in less resistance than that predicted by the method in EN 1168. ${ }^{15}$ This is attributed to the failure mode in the FE analyses, that is cracking of the upper flange, which is not taken into account in the present standard. For pure shear, the difference was small; still, for the $400 \mathrm{~mm}$ unit, the analyses showed slightly lower resistance than the method in EN 1168. This divergence may be caused by the fact that, in the present standard, only the cross-section at a distance of half of the depth away from the support (the critical point assumed in the analytical model) is used. For cross-sections with circular voids this is the most critical point, although it may not apply cross-sections with constant web widths.

The effects of shear span and the influence of the prestressing transfer zone on the shear and torsion capacities were also evaluated. As could be expected, the capacities were higher when the shear span was outside the prestressing transfer zone, except for loading close to pure torsion. The shear spans influenced the capacities; shorter shear span gave higher capacities. This indicates that it is hard to predict a shear-torsion capacity that is not influenced by the boundaries. This problem is similar, however, when using analytical methods: one assumed crack pattern is used for all load cases.

Interaction diagrams, such as those presented here, could be established for different geometries of hollow core units and used in practical design when the shear force and torsional moment are known. These action effects could be evaluated from diagrams used in practical design today, ${ }^{15}$ or by FE analyses using a simplified model of the whole floor, such as the model developed in Lundgren et al. ${ }^{14}$

Magazine of Concrete Research, 2005, 57, No. 9 


\section{Acknowledgements}

The photographs in this paper are used with kind permission of VTT. The authors would like to thank Matti Pajari, DSc(tech), at VTT for allowing us to attend the tests and to use the data collected directly after the tests were carried out. The research was financed by the 5th Framework of European Commission, the International Prestressed Hollow Core Association, the 'Bundesverband Spannbeton-Hohlplatten' in Germany and by the partners involved, which were Chalmers University of Technology, VTT, Consolis Technology, Strängbetong, Castelo and Echo.

\section{References}

1. Walraven J. C. and Mercx W. P. M. The bearing capacity for prestressed hollow core slabs. Heron, 1983, 28, No. 3, 3-46.

2. PISAnty A. The shear strength of extruded hollow-core slabs. Materials and Structures, 1992, 25, No. 148, 224-230.

3. YANG L. Design of prestressed hollow-core slabs with reference to web shear failure. Journal of Structural Engineering, ASCE, 1994, 120, No. 9, 2675-2696.

4. Jonsson E. Shear capacity of prestressed extruded hollow-core slabs. Nordic Concrete Research, 1988, No. 7, 167-187.

5. HoAng L. C. Shear Strength of Non-Shear Reinforced Concrete Elements Part 3. Prestressed Hollow-Core Slabs. Institut for baerende konstruktioner og material, Department of Structural Engineering and Materials, Technical University of Denmark, Lyngby Series R No 30, 1997.

6. Becker R. J. and Buettner D. R. Shear tests of extruded hollow-core slabs. Precast/Prestressed Concrete Institute Journal, 1985, 30, No. 2, 40-54.

7. PAJARI M. Shear resistance of prestressed hollow core slabs on flexible supports. PhD Thesis, VTT, Technical Research Centre of Finland, Espoo, 1995.

8. PAJARI M. Shear resistance of PHC slabs supported on beams. II: Analysis. Journal of Structural Engineering, ASCE, 1998, 124, No. 9, 1062-1073.

9. Gabrielsson H. Ductility of high performance concrete structures. PhD Thesis, Division of Structural Engineering, Luleå University of Technology, Luleå, 1999.
10. PAJARI M. Shear-Torsion Interaction Tests On Single Slab Units. Technical Research Centre of Finland, VTT Building and Transport, 2004, Internal report RTE50-IR-1/2003.

11. Pajari M. Pure torsion tests on single slab units. Technical Research Centre of Finland, VTT Building and Transport, December 2003, Internal report RTE50-IR-25/2002.

12. Broo H. and Lundgren K. Finite Element Analyses of Hollow Core Units Subjected to Shear and Torsion. Chalmers University of Technology, Department of Structural Engineering, Concrete Structures, Göteborg, December 2002, Report 02:17.

13. Broo H., Lundgren K. and Engström B. Shear and torsion in prestressed hollow core units: Finite element analyses of fullscale tests. Structural Concrete (submitted for publication).

14. Lundgren K., Broo, H. and Engström B. Analyses of hollow core floors subjected to shear and torsion. Structural Concrete, 2004, 5, No. 4, 1464-4177.

15. Comité Européen de Normalisation. CEN/TC229: Precast concrete products-Hollow core slabs. Final draft prEN 1168 , CEN, Brussels, 2004.

16. PAJARI M. Design of prestressed hollow core slabs. Technical Research Centre of Finland, 1989, Espoo Research Reports 657.

17. TNO. DIANA Finite Element Analysis, User's Manual release 8.1. Nederlandse Organisatie voor Toegepast-natuurwetenschappelijk Onderzoek, Building and Construction Research, Delft, The Netherlands, 2002.

18. Comité Euro-International du Béton. High Performance Concrete, Recommended Extension to the Model Code 90. Bulletin d'Information 228, CEB, Lausanne, Switzerland, 1995.

19. Comité Euro-international du Béton. CEB-FIP Model Code 1990. Bulletin d'Information 213/214, CEB, Lausanne, Switzerland, 1993.

20. Lundgren K. Steel-Encased Pull-Through Tests of Seven-Wire Strands. Department of Structural Engineering, Concrete Structures, Chalmers University of Technology, Göteborg, Sweden, 2002, Report 02:13.

21. Comité Européen dE Normalisation. CEN/TC250/SC2. Eurocode 2: Design of concrete structures-Part 1: General rules and rules for buildings, prEN 1992-1-1 Draft for Stage 49 ed. CEN, Brussels, 2002.

Discussion contributions on this paper should reach the editor by 1 May 2006 